\title{
Functioning in the fibromyalgia syndrome: validity and reliability of the WHODAS 2.0
}

\author{
Marina Carvalho Arruda Barreto ${ }^{1} \mathbb{B}$, Fabianna Resende Jesus Moraleida² ${ }^{2}$, Cristiane Vitaliano Graminha ${ }^{3}$, \\ Camila Ferreira Leite ${ }^{2} \mathbb{D}$, Shamyr Sulyvan Castro ${ }^{2}$ a and Ana Carla Lima Nunes ${ }^{2 *}$ (D)
}

\begin{abstract}
Background: Fibromyalgia syndrome (FMS) is both a challenging and disabling condition. The International Association for the Study of Pain (IASP) classifies FMS as chronic primary pain, and it can negatively impact individuals' functioning including social, psychological, physical and work-related factors. Notably, while guidelines recommend a biopsychosocial approach for managing chronic pain conditions, FMS assessment remains clinical. The WHODAS 2.0 is a unified scale to measure disability in the light of the International Classification of Functioning, Disability and Health. Thus, this study aimed to evaluate the reliability and validity of the Brazilian version of WHODAS 2.0 for use in individuals with FMS.

Methods: Methodological study of the validity and reliability of the Brazilian version of the 36-item WHODAS 2.0 with 110 individuals with FMS. The instrument gives a score from 0 to 100, the higher the value, the worse the level of functioning. We assessed participants with Medical Outcomes Study 36-Item Short-Form Health Survey (SF-36) (0-100), Fibromyalgia Impact Questionnaire (FIQ) (0-10) and Beck Depression Inventory instrument (BDI) (0-63). The construct validity, internal consistency, and test-retest stability. We used SF-36, FIQ and BDI to study construct validity analysis. For statistical analysis, we performed the intraclass correlation (ICC), Spearman correlation, and Cronbach's alpha, with a statistical level of $5 \%$.
\end{abstract}

Results: Most participants were female $(92.27 \%)$, aged $45( \pm 15)$ years. The test-retest reliability analysis $(n=50)$ showed stability of the instrument (ICC $=0.54 ; \rho=0.84, p<0.05)$. The test-retest correlation between the domains was moderate to strong $(\rho>0.58$ and $<0.90)$. Internal consistency was satisfactory for total WHODAS $2.0(0.91)$ and also for domains, ranging from 0.44 to 0.81 . The construct validity showed satisfactory values with all moderately correlated with WHODAS 2.0 instruments $(>0.46$ and $<0.64 ; p<0.05$ ). WHODAS 2.0 evaluates the functioning encompassing components of health-related quality of life, functional impact, and depressive symptoms in those with FMS.

Conclusions: WHODAS 2.0 is a reliable and valid instrument to evaluate functioning of Brazilians with FMS. It provides reliable information on individuals' health through of a multidimensional perspective, that allows for individualcentered care.

Keywords: Fibromyalgia syndrome, Disability, Chronic pain, Patient reported outcome measures, WHO

*Correspondence: aclnunes@gmail.com

2 Department of Physical Therapy, Federal University of Ceará, Major Weyne Street, 1440, Fortaleza, CE 60430-450, Brazil

Full list of author information is available at the end of the article

\section{Background}

Fibromyalgia Syndrome (FMS) is a disabling health condition that deserves to be highlighted [1]. The International Association for the Study of Pain (IASP) classifies FMS as chronic primary pain [2], and it can negatively impact patients' functioning including social, psychological, physical and work-related factors[3]. Notably, while 
guidelines recommend a biopsychosocial approach for managing chronic pain $[4,5]$ FMS assessment remains clinical.

FMS has an uncertain diagnosis due to reliance on patient report of subjective symptoms, absence of a universally accepted diagnostic gold standard, and lack of a specific biomarker[1]. There is a disagreement between FMS criteria and clinician-based FMS diagnoses that suggests bias in the identification of this health condition[6]. Furthermore, individuals with FMS tend to report a complex set of concerns, including fatigue, sleep dysfunction, stiffness, depression, anxiety, poor physical capacity, and cognitive disturbance in addition to musculoskeletal pain $[7,8]$. These should be described as negative aspect of functioning associated with chronic pain[3].

Increased attention to the functional impact of chronic pain is an important step forward for its management. Functioning is a relevant indicator of population health[9], as it considers the dynamic interaction between a person's health status and contextual factors[10]. The analysis of the functioning covers the structures and functions of the body, activities and participation, in addition to contextual factors, which allows to understand and measure the health status through of a multidimensional perspective $[9,11]$. This concept of functioning and its application as well as the term disability, were proposed by International Classification of Functioning, Disability and Health (ICF) based on the biopsychosocial model [10, 12].

Considering the fact that people with one and the same clinical condition can vary substantially in terms of disability, there is a need to expand the assessment tools [3]. The instruments commonly used to assess outcomes in FMS are not aligned with all categories of functioning as defined by the ICF[13, 14]. The World Health Organization Disability Assessment Schedule 2.0 (WHODAS 2.0) is a tool that measure functioning based on the theoretical conceptual framework of the ICF.

The WHODAS 2.0 is a generic instrument that provides the level of functioning in the following six domains: cognition, mobility, self-care, getting along, life activities, and participation, and its psychometric properties are considered satisfactory[15]. The 12-item version of WHODAS 2.0 has already been validated for the population with FMS in the United States[16]. The 36-item version of WHODAS 2.0 is the most detailed and it allows users to generate scores for the six domains of functioning and to calculate an overall functioning score[15]. This version is not validated to evaluate individuals with FMS. Knowledge of the functioning profile of individuals with FMS is needed for more appropriate and effective clinical management, especially because FMS is a multifactorial and multisystemic condition[13]. The multimodal pain management approach refers to a biopsychosocial model of pain that directs attention to suffering, Quality of Life (QoL), and participation in family and other areas of social life[3]. The WHODAS 2.0 emerges as an alternative to address this shortage. With the validation of this instrument, a tool to globally and efficiently assess individuals with FMS will be available. The aim of our study was to evaluate the validity and reliability of the WHODAS 2.0 (Brazil) for individuals with FMS.

\section{Materials and methods}

This was a methodological study that evaluated the psychometric properties of the WHODAS 2.0 (Brazil) instrument in people with FMS. The measurement properties were defined according to the recommendations of the COnsensus-based Standards for the selection of health Measurement INstruments (COSMIN)[17].

\section{Participants}

Recruitment occurred through the referral of health professionals, active searching in a health unit, and social media dissemination. Eligible participants were male or female, 18 years of age or older, who met the FM diagnostic criteria of the 1990 American College of Rheumatology[18].

Individuals who presented any disease or disorder that led to some functional impairment that was not linked to the characteristics of FMS and/or cognitive impairment that prevented them from responding to the instruments were excluded from the study. The minimum sample size to meet the necessary criteria of the validation process was 100 individuals[19].

Our study included 110 participants and was approved by the Research Ethics Committee (n.1.918.391), in accordance with the ethical standards of the institutional and/or national research committee and with the 1964 Helsinki Declaration. All participants were informed of the objectives of the study and gave written consent for their voluntary participation in the study and the anonymous use of personal data in statistical analyses.

\section{Outcomes \\ Functioning - world health organization disability assessment schedule 2.0 (WHODAS 2.0)}

The functioning was measured by WHODAS 2.0 in the following six domains: cognition, mobility, self-care, getting along, life activities, and participation. For the purpose of this study, we used the interview 36-item version. It allows for scoring each domain, and the general functioning score. Each domain and the total score range from 0 to 100 , where a score closer to 100 indicates worse functioning of the individual. This instrument has excellent psychometric properties based on the strong 
test-retest reliability values found in a study conducted in 36 countries[15]. WHODAS was translated and crosscultural adapted to the Brazilian Portuguese and the final version was approved by WHO [20].

\section{Fibromyalgia impact-fibromyalgia impact questionnaire (FIQ)}

This instrument assesses the impact of FMS on QoL. It is currently the most widely used questionnaire in clinical practice and research and is used to assess the health status of individuals with FMS. The FIQ has 19 goal character items divided into 10 questions related to function, overall impact and symptoms. The final score ranges from 0 to 10; the higher the score, the greater the impact on QoL[21].

\section{Quality of life-medical outcomes study 36- item short-form health survey (SF-36)}

The SF-36 is a generic multidimensional questionnaire that is used to assess the self-perception of QoL and health status. Its 36 items encompass eight domains, namely: physical functioning, role physical, bodily pain, general health, vitality, social functioning, role emotional, and mental health. The final score is separated by domains, where each value can be between 0 and 100; the closer the value is to 100 , the better the respondent's QoL. The instrument presented significant results and satisfactory values for intra- and inter-rater correlation. The same was found in the construct validity analysis[22].

\section{Depressive symptoms-beck depression inventory (BDI)}

The instrument was used to detect depressive symptoms. The instrument has 21 items, ranging from 0 to 3 points. The higher the individual's score, the greater the likelihood of depressive symptoms, which should be confirmed with other diagnostic tests. The instrument presented high internal consistency (0.81), and significant values, and strong correlation in the construct validity[23].

\section{Procedures}

The researchers were previously trained to apply the instruments and to confirm the diagnostic criteria for FMS. Data collection occurred in a reserved room at the universities from August 2017 to July 2019.

Categorical sociodemographic variables (gender, race, marital status, profession, comorbidity, pain body places) and continuous variables (age, number of children, years of schooling, symptom evolution time, medications, numerical rating scale-NRS) were collected by means of an evaluation questionnaire prepared by the researchers. NRS is a measure of pain intensity of 11 points (0-10). Score zero means no pain and score 10 means worst pain[24]. For eligible individuals, the WHODAS 2.0, FIQ, SF-36, and BDI instruments were applied. After 7 days, participants returned to perform the retest with the same researcher, who applied the WHODAS 2.0 instrument.

\section{Statistical analysis}

The validation process was composed of the analysis of the following psychometric properties: reliability, internal consistency, and construct validity. The analysis included the subjects who answered all necessary items of the instruments. For test-retest reliability measurement, data from 50 subjects were analyzed, a number considered adequate for analysis[19]. For the analysis of the other psychometric properties, 110 individuals were included.

Test-retest reliability is obtained when the same instrument is applied twice to the same subject with an interval of seven days between applications. The instrument is considered stable when the coefficient values are greater than $0.7[25,26]$.

Internal consistency evaluates the relationship between instrument sub-items within the same domain. This was evaluated using Cronbach's alpha, which analyses the degree of covariance between the sub-items. The instrument has good internal consistency when its domains present Cronbach's alpha values between 0.7 and $0.95[26]$.

Construct validity investigate validity of an instrument in relationships with other outcomes measures of good quality[27]. This property was measured by application of another instrument that has already been validated for the same population. Correlation values greater than 0.7 indicate strong correlation[26, 28]. For this evaluation, the correlation between the WHODAS 2.0 and the FIQ and SF-36 instruments, which are widely used for FMS and QoL impact analysis, respectively, was performed. In addition, the correlation between the WHODAS 2.0 domains and SF-36 domains, FIQ and BDI was analyzed. Table 1 shows plausible relationships between WHODAS 2.0 domains and SF36, FIQ, BDI.

To describe the clinical, sociodemographic, and functioning characteristics of the study participants, the following descriptive measures were used: measures of central tendency (mean), dispersion (standard deviation), and relative frequency (\%). The collected data were analyzed using the Stata program, adopting a significance level of $\alpha=0.05$.

Initially, the normality of the data was tested with the Kolmogorov-Smirnov test[29]. Test-retest reliability was analyzed using the intraclass correlation coefficient (ICC), followed by the Spearman correlation test between the WHODAS 2.0 domain and total values found in the test and retest. This strategy of using two 
Table 1 Hypothesized correlations between the WHODAS 2.0 domains, total WHODAS 2.0 and the SF36, FIQ and BDI instruments

\begin{tabular}{lccc}
\hline WHODAS 2.0 & SF36 & FIQ & BDI \\
\hline Cognition & $\checkmark$ & & $\checkmark$ \\
Mobility & $\checkmark$ & \\
Self-Care & $\checkmark$ & & \\
Getting along & $\checkmark$ & & \\
Life activity & $\checkmark$ & \\
Work activity & & \\
Domestic activity & $\checkmark$ & $\checkmark$ \\
Participation & $\checkmark$ & \\
Total & $\checkmark$ & $\checkmark$ \\
\hline
\end{tabular}

statistical tests is due to the nature of the tests in association with the characteristics of FM. The ICC is a measure of agreement. The correlation is considered strong when the value is higher than 0.7 , moderate when it is between 0.4 and 0.7 , and weak when it is less than $0.4[30]$. We verified the internal consistency according to Cronbach's alpha. To assess the construct validity, we use the Spearman correlation test between the domains and the total WHODAS 2.0 score, and FIQ and SF-36.

\section{Results}

We evaluated 110 people with a diagnosis of FMS. The participant data and the average value of the instruments are described in Table 2. The sample consisted primarily of women $(97.27 \%)$, aged $44.66( \pm 14.69)$ years, who had paid work $(21.82 \%)$ or were unemployed due to health problems (19.09\%). The pain intensity level was 6.38 $( \pm 2.56)$.

The measures referring to the instrument's psychometric properties are described in Table 3. Results indicate satisfactory values for internal consistency. In the testretest reliability, we found between moderate to high ICC values (except for life activities, whose work activities were not responded by $57 \%$ of the sample), and the correlation coefficient was moderate to strong.

In the construct validity analysis, the WHODAS 2.0 showed a moderate and significant correlation with the SF-36, FIQ, and BDI. The WHODAS 2.0 domains, except for the work activity domain, showed a moderate and significant correlation with SF-36. The mobility domain and domestic activity (life activities domain) of the WHODAS 2.0 showed a moderate and significant correlation with the FIQ, and the domains of cognition and getting along showed a moderate and significant correlation with the total BDI value (Table 4).

\section{Discussion}

Our study showed that the WHODAS 2.0 is a valid and reliable instrument to measure functioning in individuals with FMS, presenting adequate psychometric properties. The WHODAS 2.0 assesses functioning of individuals with FMS, incorporating aspects of health-related QoL, functional impact, and depressive symptoms. The WHODAS 2.0 offers the opportunity to evaluate the chronic patient, as in osteoarthritis[31] or rheumatoid arthritis, according to the ICF biopsychosocial model.

The WHODAS 2.0 maintains excellent internal consistency when evaluating individuals with FM. In this way, issues from the same domain and from the entire instrument are adequately related, and the interpretation of the scores reflects the level of functioning[32, 33]. Studies that evaluated the psychometric properties of the WHODAS 2.0 in musculoskeletal and rheumatic conditions found similar results[34, 35].

Additionally, our findings showed acceptable testretest reliability but the domains of life activity and participation showed less stability in individuals with FMS after one week. These results are probably due to FMS being a health condition with a wide variety of transient symptoms[13, 36], and changes may occur between two time points. We hypothesize that the WHODAS 2.0 is capable of detecting minimal changes in these domains, however, the responsiveness of this instrument needs to be tested in a future study. The application of instruments addressing general health at the time of reapplication of the WHODAS 2.0 could confirm this hypothesis.

The WHODAS 2.0 is an instrument that includes all ICF concepts for the evaluation of functioning[15]. Our validation results reinforced the multidimensional nature of this instrument, which covers part of the domains of the three investigated instruments such as QoL, functional impact and depressive symptoms. Additionally, the WHODAS 2.0 covers other aspects not included in this questionnaires[37]. The 12-item version WHODAS 2.0 was related to fatigue, pain, sleep difficulties, cognitive impairment, depression, and social support in individuals with FMS[16].

The scores of the investigated questionnaires were related to some of the WHODAS 2.0 domains. An example is FIQ, which had a moderate correlation with two WHODAS 2.0 domains, mobility and life activities (domestic activity). These results demonstrated whereas FIQ is a specific instrument for assessing the health impact of individuals with FM[21], it fails to evaluate other functioning related domains such as cognition, self-care, and getting along. According to Prodinger et al. 
Table 2 Description of the sociodemographic, clinical, and functional characteristics

\begin{tabular}{|c|c|c|}
\hline Variable & $\mathbf{n}$ & $\%(100)$ \\
\hline \multicolumn{3}{|l|}{ Sex } \\
\hline Woman & 107 & 92.27 \\
\hline Man & 3 & 2.73 \\
\hline \multicolumn{3}{|l|}{ Marital status } \\
\hline Never married & 38 & 34.86 \\
\hline Currently married & 42 & 38.53 \\
\hline Separated & 9 & 8.26 \\
\hline Divorced & 15 & 13.76 \\
\hline Widower & 3 & 2.75 \\
\hline Cohabiting & 2 & 1.83 \\
\hline \multicolumn{3}{|l|}{ Race $^{\mathrm{a}}$} \\
\hline White & 14 & 16.86 \\
\hline Brown & 35 & 42.16 \\
\hline Negro & 30 & 36.14 \\
\hline Indigenous & 4 & 4.82 \\
\hline \multicolumn{3}{|l|}{ Income $e^{a}$} \\
\hline Less than 1 minimum Brazilian wage & 15 & 18.07 \\
\hline 1-2 minimum Brazilian wage & 38 & 45.78 \\
\hline 3-5 minimum Brazilian wage & 23 & 27.72 \\
\hline More than 5 minimum Brazilian wage & 7 & 8.43 \\
\hline \multicolumn{3}{|l|}{ Work activity } \\
\hline Paid work & 24 & 21.82 \\
\hline Freelance & 13 & 11.82 \\
\hline Non-paid work, such as volunteer or charity & 2 & 1.82 \\
\hline Student & 11 & 10 \\
\hline Homemaker & 14 & 12.73 \\
\hline Retired & 12 & 10.91 \\
\hline Unemployed (health reasons) & 21 & 19.09 \\
\hline Unemployed (other reasons) & 5 & 4.54 \\
\hline \multirow[t]{2}{*}{ Other } & 8 & 7.27 \\
\hline & Mean & Standard deviation \\
\hline Age & 44.66 & 14.69 \\
\hline How many years spent studying & 16.10 & 8.83 \\
\hline$N R S^{\mathbf{a}}$ & 6.38 & 2.56 \\
\hline FIQ & 6.73 & 1.55 \\
\hline$\left.\mathrm{BD}\right|^{\mathrm{a}}$ & 22.59 & 10.21 \\
\hline \multicolumn{3}{|l|}{ WHODAS 2.0} \\
\hline Cognition & 43.63 & 20.23 \\
\hline Mobility & 55.73 & 20.72 \\
\hline Self-care & 27.18 & 22.67 \\
\hline Getting along & 32.04 & 23.52 \\
\hline Life activity & 46.70 & 21.62 \\
\hline Domestic activity & 7.1.54 & 22.14 \\
\hline Work activity & 60.10 & 20.56 \\
\hline Participation & 55.00 & 19.92 \\
\hline Total & 44.97 & 14.93 \\
\hline \multicolumn{3}{|l|}{ SF36 } \\
\hline Physical functioning & 36.10 & 17.70 \\
\hline Role physical & 17.65 & 21.04 \\
\hline
\end{tabular}


Table 2 (continued)

\begin{tabular}{lll}
\hline & Mean & Standard deviation \\
\hline Bodily pain & 23.45 & 20.25 \\
General health & 37.97 & 23.13 \\
Vitality & 24.93 & 21.63 \\
Social functioning & 39.95 & 23.41 \\
Role emotional & 29.37 & 34.15 \\
Mental health & 49.85 & 22.02 \\
Total & 32.92 & 12.53 \\
\hline
\end{tabular}

a Value referring to 83 individuals with FMS. NRS = Numeric Rating Scale; FIQ = Fibromyalgia Impact Questionnaire; WHODAS=World Health Organization Disability Assessment Schedule; SF36 = Medical Outcomes Study 36- Item Short-Form Health Survey; BDI = Beck Depression Index

Table 3 Reliability (Cronbach's a and ICC) of the WHODAS 2.0 domains

\begin{tabular}{llll}
\hline Domains WHODAS 2.0 & Cronbach's a & ICC (95\%) & Test-retest correlation coefficient \\
\hline Cognition & 0.77 & $0.61(0.34-0.87)$ & $0.83^{*}$ \\
Mobility & 0.81 & $0.79(0.40-0.95)$ & $0.90^{*}$ \\
Self-care & 0.76 & $0.67(0.40-0.95)$ & $0.79^{*}$ \\
Getting along & 0.73 & $0.67(0.41-0.93)$ & $0.65^{*}$ \\
Life activity & 0.44 & $0.41(0.07-0.74)$ & $0.62^{*}$ \\
Domestic activity & 0.62 & $0.31(0.00-0.67)$ & $0.65^{*}$ \\
Work activity & 0.53 & $0.49(0.06-0.92)$ & $0.58^{*}$ \\
Participation & 0.80 & $0.26(0.00-0.60)$ & $0.59^{*}$ \\
Total & 0.91 & $0.54(0.13-0.95)$ & $0.84^{*}$
\end{tabular}

${ }^{*} p<0.05 ;$ WHODAS $=$ World Health Organization Disability Assessment Schedule

Table 4 Correlation coefficient matrix between the domains of WHODAS 2.0, SF36, BDI and FIQ

WHODAS 2.0 Domains

Cognition Mobility Self-care Getting along Life activity Work activity Domestic Participation Total

\begin{tabular}{|c|c|c|c|c|c|c|c|c|c|}
\hline \multicolumn{10}{|l|}{ SF 36} \\
\hline SF36 Total & $-0.4055^{*}$ & $-0.4716^{*}$ & $-0.5394^{*}$ & $-0.5462^{*}$ & $-0.4436^{*}$ & -0.2242 & $-0.5522^{*}$ & $-0.4819^{*}$ & $-0.6435^{*}$ \\
\hline $\begin{array}{l}\text { Physical Function- } \\
\text { ing }\end{array}$ & $-0.3403^{*}$ & $-0.5581^{*}$ & $-0.4397^{*}$ & -0.2362 & $-0.4917^{*}$ & $-0.3756^{*}$ & $-0.4509^{*}$ & $-0.2828^{*}$ & $-0.4894^{*}$ \\
\hline Role Physical & -0.1648 & -0.2165 & $-0.3209^{*}$ & -0.2201 & -0.2657 & -0.0394 & $-0.4692^{*}$ & $-0.3264^{*}$ & $-0.3301^{*}$ \\
\hline Bodily Pain & -0.1658 & -0.1783 & -0.0933 & 0.0319 & -0.1750 & -0.0431 & -0.2258 & -0.0593 & $-0,2001^{*}$ \\
\hline General Health & -0.2017 & $-0.3715^{*}$ & $-0.5347^{*}$ & $-0.3230^{*}$ & $-0.4297^{*}$ & -0.2075 & $-0.5094^{*}$ & $-0.3377^{*}$ & $-0.4483^{*}$ \\
\hline Vitality & $-0.2821^{*}$ & $-0.3880^{*}$ & $-0.3269^{*}$ & -0.1622 & -0.1715 & -0.0124 & $-0.3146^{*}$ & $-0.3150^{*}$ & $-0.4100^{*}$ \\
\hline $\begin{array}{l}\text { Social Function- } \\
\text { ing }\end{array}$ & $-0.3268^{*}$ & -0.2279 & -0.1436 & $-0.3691^{*}$ & $-0.2875^{*}$ & -0.2328 & -0.2485 & -0.2066 & $-0.3664^{*}$ \\
\hline Role Emotional & -0.0244 & -0.0095 & $-0.2995^{*}$ & $-0.3411^{*}$ & -0.1032 & -0.0236 & -0.1586 & -0.0353 & -0.1165 \\
\hline Mental Health & $-0.3287^{*}$ & -0.2005 & -0.0588 & $-0.3317^{*}$ & -0.1434 & -0.1130 & -0.1517 & $-0.2844^{*}$ & $-0.2832^{*}$ \\
\hline FIQ & $0.3419^{*}$ & $0.4355^{*}$ & $0.3105^{*}$ & 0.1857 & $0.3894^{*}$ & 0.1833 & $0.4640^{*}$ & 0.3615 & $0.4857^{*}$ \\
\hline BDI & $0.5005^{*}$ & $0.3767^{*}$ & 0.2828 & $0.5276^{*}$ & 0.2643 & 0.2528 & 0.2387 & 0.2866 & $0.4616^{*}$ \\
\hline
\end{tabular}

${ }^{*} p<0.05 ; \mathrm{FIQ}=$ Fibromyalgia Impact Questionnaire; WHODAS = World Health Organization Disability Assessment Schedule; SF36= Medical Outcomes Study 36- Item Short-Form Health Survey; BDI = Beck Depression Index

[38], a specific instrument might raise difficulties associated with the multidimensionality and functioning. This more detailed analysis according to the WHODAS
2.0 domains allows to identify typical disabilities of the FMS[3], which cannot be performed in the 12-item version of WHODAS[15]. 
We observed that higher scores on health-related QoL were related to a better functioning profile in WHODAS 2.0. The total score of the SF-36 showed moderate correlation in 7 of the 8 domains of the WHODAS 2.0. However, neither the mental health, role emotional nor the bodily pain SF-36 domains seem to be well explored in WHODAS 2.0. These findings support the use of the SF-36 as an outcome which complements WHODAS 2.0, as suggested Garin et al.[35], who correlated the WHODAS 2.0 with the SF-36 for individuals with different chronic diseases, and showed a moderate correlation in all analyses. Xenouli et al.[39] divided the SF-36 domains into two blocks, physical and mental health, and correlated them with the total value of the WHODAS 2.0. The correlation between the total score of the WHODAS 2.0 and the physical health SF-36 component was strong $(r=-0.76)$ in Greeks with or without disabilities, while the correlation was moderate between the WHODAS 2.0 and the SF-36 mental health component $(-0.50)$ [39]. SF-36 was chosen because it is a generic questionnaire that makes a global analysis of the QoL of the individual[22].

The moderate correlation between BDI and WHODAS 2.0 suggests that important aspects of depressive symptoms are covered in this functioning tool, especially through the domains of cognition, mobility and getting along with people. Still it SF-36 and the BDI assess different outcomes when compared to the WHODAS 2.0[22, 23]. In addition, the instruments refer to different periods of symptom presentation, which can influence the patient's report[21, 23]. Still, these instruments were included because they are the most used to assess individuals with FMS. Our study is the first to investigate the correlation of the WHODAS 2.0 with FIQ and BDI.

We had some limitations in this study. We did not reapply a concurrent instrument at the time of the second application of the WHODAS 2.0, which limits the perception of individual conditions on the day of the retest. Another limitation is the functioning in life activities because it includes the work activities that are not applied to all individuals. We highlight that the findings of the present study are unprecedented since the psychometric properties of the the 36-item version WHODAS 2.0 have not been tested for FMS individuals.

\section{Conclusions}

We propose the WHODAS 2.0 as a reliable and valid instrument for assessing functioning of individuals with FM. It provides reliable information on individuals' health based on structures and functions of the body, activities and participation, in addition to contextual factors, that allows for individual-centered care. Based on our findings we recommend using the instrument to assess health status and to monitor health interventions.

\begin{abstract}
Abbreviations
FMS: Fibromyalgia syndrome; QoL: Quality of life; ICF: International classification of functioning, disability and health; WHODAS 2.0: World health organization disability assessment schedule 2.0; FIQ: Fibromyalgia Impact Questionnaire; SF-36: Medical outcomes study 36-item short-form health survey; BDI: Beck depression inventory; NRS: Numerical rating scale; ICC: Intraclass correlation coefficient.
\end{abstract}

\section{Acknowledgements \\ To the Movement project of the Department of Physiotherapy, Federal Univer- sity of Ceará.}

\section{Authors' contributions}

MCAB collected data, contributed to the writing of the article, statistical analysis and final review; FRJM contributed to data collection, article writing and final review; CVG contributed to data collection and final review; CCL contributed to the writing of the article and final review; SSC performed the statistical analysis, contributed to the writing of the article and final review; ACLN supervised the project, contributed to data collection, statistical analysis, article writing and final review. All authors read and approved the final manuscript.

\section{Funding}

This research did not receive any specific grant from funding agencies in the public, commercial, or not-for-profit sectors.

\section{Availability of data and materials}

The datasets used and/or analyzed during the current study are available from the corresponding author on reasonable request.

\section{Declarations}

Ethics approval and consent to participate

This study was approved by the Research Ethics Committee of the University of Triângulo Mineiro (1.918.391).

\section{Consent for publication}

Not applicable.

\section{Competing interests}

The authors declare that they have no competing interests.

\section{Author details}

1Department of Public Health, Universidade Federal do Ceará, Ceará, Fortaleza, Brazil. ${ }^{2}$ Department of Physical Therapy, Federal University of Ceará, Major Weyne Street, 1440, Fortaleza, CE 60430-450, Brazil. ${ }^{3}$ Department of Physical Therapy, Universidade Federal do Triângulo Mineiro, Ceará, Uberaba, Brazil.

Received: 6 July 2021 Accepted: 6 September 2021

Published online: 16 September 2021

References

1. Benlidayi IC. Fibromyalgia as a challenge for patients and physicians. Rheumatol Int. 2018;38(12):2345. https://doi.org/10.1007/ s00296-018-4138-6.

2. Treede R-D, RiefW, Barke A, et al. Chronic pain as a symptom or a disease: the IASP Classification of Chronic Pain for the International Classification of Diseases (ICD-11). Pain. 2019;160(1):19-27.

3. Nugraha B, Gutenbrunner C, Barke A, et al. The IASP classification of chronic pain for ICD-11: functioning properties of chronic pain. Pain. 2019;160(1):88-94. 
4. Macfarlane GJ, Kronisch C, Dean LE, et al. EULAR revised recommendations for the management of fibromyalgia. Ann Rheum Dis. 2017;76(2):318-28. https://doi.org/10.1136/annrheumdis-2016-209724.

5. Clauw DJ, Essex MN, Pitman V, et al. Reframing chronic pain as a disease not a symptom: rationale and implications for pain management. Postgrad Med. 2019;131(3):185-98. https://doi.org/10.1080/00325481.2019. 1574403.

6. Marques AP, Santo ASE, Berssaneti AA, et al. A prevalência de fibromialgia: atualização da revisão de literatura. Rev Bras Reumatol. 2017;57(4):35663. https://doi.org/10.1016/j.rbre.2017.01.005.

7. Wolfe F, Smythe HA, Yunus MB, et al. The American College of Rheumatology 1990 Criteria for the Classification of Fibromyalgia. Report of the multicenter criteria committee. Arthritis Rheum. 1990;33(2):160-72. https://doi.org/10.1002/art.1780330203.

8. Sempere-rubio N, Aguilar-rodriguez M, Ingl M, et al. Physical condition factors that predict a better quality of life in women with fibromyalgia. Int J Environ Res Public Health. 2019

9. Stucki G, Bickenbach J. Functioning: the third health indicator in the health system and the key indicator for rehabilitation. Eur J Phy Rehabil Med. 2017:53(1):134-8. https://doi.org/10.23736/s1973-9087.17.04565-8

10. World Health Organization - WHO. International Classification of Functioning, Disability and Health (ICF). Genebra; 2001.

11. Üstün TB, Chatterji S, Bickenbach J, et al. The international classification of functioning, disability and health: a new tool for understanding disability and health. Disabil Rehabil. 2003;25(11-12):565-71. https://doi.org/10. 1080/0963828031000137063.

12. Farias N, Buchalla CM. A Classificação Internacional de Funcionalidade, Incapacidade e Saúde da Organização Mundial da Saúde: Conceitos. Usos e Perspectivas Rev Bras Epidemiol. 2005;8(2):187-93. https://doi.org/ 10.1590/S1415-790X2005000200011.

13. Lupi JB, Abreu DCC, Ferreira MC, et al. Brazilian Portuguese version of the Revised Fibromyalgia Impact Questionnaire (FIQR-Br): cross-cultural validation, reliability, and construct and structural validation. Disabil Rehabil. 2017;39(16):1650-63. https://doi.org/10.1080/09638288.2016.1207106.

14. Costa IS, Gamundí A, Miranda JGV, et al. Altered functional performance in patients with fibromyalgia. Front Hum Neurosci. 2017;1:1-9. https:// doi.org/10.3389/fnhum.2017.00014

15. Castro SS, Leite CF, Osterbrock C, et al. Avaliação de Saúde e Deficiência: Manual do WHO Disability Assessment Schedule (WHODAS 2.0). Uberaba: Universidade Federal do Triângulo Mineiro - UFTM; 2015. 153 p.

16. Smedema SM, Yaghmaian RA, Ruiz D, et al. Psychometric validation of the world health organization disability assessment schedule 2.0-12-item Version in persons with fibromyalgia syndrome. Journal of Rehabilitation. 2016;82(2).

17. Mokkink LB, Terwee CB, Patrick DL, et al. The COSMIN checklist for assessing the methodological quality of studies on measurement properties of health status measurement instruments: an international Delphi study. Qual Life Res. 2010;19(4):539-49. https://doi.org/10.1007/ s11136-010-9606-8.

18. Wolfe F, Clauw DJ, Fitzcharles MA, et al. The American College of Rheumatology preliminary diagnostic criteria for fibromyalgia and measurement of symptom severity. Arthritis Care Res. 2010;62(5):600-10. https://doi. org/10.1002/acr.20140.

19. Terwee CB, Bot SDM, de Boer MR, et al. Quality criteria were proposed for measurement properties of health status questionnaires. J Clin Epidemiol. 2007;60(1):34-42. https://doi.org/10.1016/j.jclinepi.2006.03.012.

20. Castro SS, Leite CF. Translation and cross-cultural adaptation of the World Health Organization Disability Assessment Schedule - WHODAS 2.0. Fisioter Pesqui. 2017;24(4):385-91. https://doi.org/10.1590/1809-2950/17118 724042017

21. Marques AP, Barsante Santos AM, Assumpção A, et al. Validação da versão Brasileira do Fibromyalgia Impact Questionnaire (FIQ). Rev Bras Reumatol. 2006;46(1):24-31. https://doi.org/10.1590/S0482-50042006000100006.

22. Ciconelli RM, Ferraz MB, Santos W, Meinão I, Quaresma MR. Tradução para a língua portuguesa e validação do questionário genérico de avaliação de qualidade de vida SF-36 (Brasil SF-36). Revista Brasileira De Reumatologia. 1999;39:143-50. Available from: http://www.scopus.com/inward/
record.url?eid=2-s2.0-0032808921\&partnerlD=40\&md5 $=8 \mathrm{e} 372 \mathrm{f} 8 \mathrm{e} 7 \mathrm{f}$ eece5ae4fc33228a55d3a8

23. Gorestein C, Andrade LHSG. Inventário de depressão de Beck : propriedades psicométricas da versão em português. 1998;(December 2015).

24. Hjermstad MJ, Fayers PM, Haugen DF, et al. Studies comparing Numerical Rating Scales, Verbal Rating Scales, and Visual Analogue Scales for assessment of pain intensity in adults: a systematic literature review. J pain symptom manage. 2011;41(6):1073-93. https://doi.org/10.1016/j.jpain symman.2010.08.016

25. Roberts P. Reliability and validity in research. Nurs Stand. 2006;20(22):41-5.

26. Souza AC, Alexandre NMC, Guirardello EB, et al. Propriedades psicométricas na avaliação de instrumentos: avaliação da confiabilidade e da validade. Epidemiol Serv Saúde. 2017;26(3):649-59. https://doi.org/10. 5123/S1679-49742017000300022.

27. Boateng GO, Neilands TB, Frongillo EA, et al. Best practices for developing and validating scales for heath, social and behavioral research: a primer. Front Public Health. 2018;6(June):1-18. https://doi.org/10.3389/fpubh. 2018.00149.

28. Polit DF. Assessing measurement in health: Beyond reliability and validity Internat J Nurs Stud. 2015;52(11):1746-53. https://doi.org/10.1016/j.ijnur stu.2015.07.002

29. Koo TK, Li MY. A Guideline of Selecting and Reporting Intraclass Correlation Coefficients for Reliability Research. J Chiropractic Med. 2016;15(2):155-63. https://doi.org/10.1016/j.jcm.2016.02.012.

30. Cohen J. Statistical power analysis for the behavioral sciences [Internet]. Vol. 2nd, Statistical Power Analysis for the Behavioral Sciences. 1988. p. 567. Available from: http://books.google.com/books?id=TION2IRAO9oC\& pgis $=1$

31. Kutlay S, Küçükdeveci AA, Elhan AH, et al. Validation of the World Health Organization disability assessment schedule II (WHODAS-II) in patients with osteoarthritis. Rheumatol int. 2011;31(3):339-46. https://doi.org/10. 1007/s00296-009-1306-8.

32. Streiner DL. Starting at the beginning: An introduction to coefficient alpha and internal consistency. J Pers Assess. 2003;80(1):99-103. https:// doi.org/10.1207/S15327752JPA8001_18.

33. Henson RK. Understanding internal consistency reliability estimates: A conceptual primer on coefficient alpha. Meas Eval Couns Dev. 2001;34(3):177-89. https://doi.org/10.1080/07481756.2002.12069034.

34. Baron M, Schieir $\mathrm{O}$, Hudson M, et al. The clinimetric properties of the World Health Organization disability assessment schedule II in early inflammatory arthritis. Arthritis Rheum. 2008:59(3):382-90. https://doi. org/10.1002/art.23314.

35. Garin O, Ayuso-Mateos $\rfloor$, Almansa J, et al. Validation of the World Health Organization Disability Assessment Schedule, WHODAS-2 in patients with chronic diseases. Health qual life outcomes. 2010;8:51. https://doi.org/10. 1186/1477-7525-8-51.

36. Oliveira RM, Leite ACS, da Silva LMS, et al. Comparative analysis of functional capacity among women with fibromyalgia and low back pain. Rev Dor. 2013;14(1):39-43. https://doi.org/10.1590/S1806-001320130001000 10.

37. Burckhardt CS, Clark SR, Bennett RM. The Fibromyalgia Impact Questionnaire: developed and validation. J Rheumatol. 1991;18(5):728-33.

38. Prodinger B, Cieza A, Williams DA, et al. Measuring health in patients with fibromyalgia: Content comparison of questionnaires based on the international classification of functioning, disability and health. Arthritis Rheum. 2008:59(5):650-8. https://doi.org/10.1002/art.23559.

39. Xenouli G, Xenoulis K, Sarafis P, et al. Validation of the World Health Organization Disability Assessment Schedule (WHO-DAS II) in Greek and its added value to the Short Form 36 (SF-36) in a sample of people with or without disabilities. Disabil Health J. 2016;9(3):518-23. https://doi.org/ 10.1016/j.dhjo.2016.01.009

\section{Publisher's Note}

Springer Nature remains neutral with regard to jurisdictional claims in published maps and institutional affiliations. 